\title{
ENTRE O LEGAL E O PERCEBIDO: INACESSIBILIDADE EM HABITAÇÃO DE INTERESSE SOCIAL NA COMUNIDADE TIMBÓ-PB
}

\author{
FARIAS, Gianna Guedes Pereira Monteiro (1); \\ MEDEIROS, Adriana Araujo de (2); \\ COSTA, Angelina Leão Dias (3);
}

(1) Universidade Federal da Paraíba (UFPB), Mestranda, gianna_farias@hotmail.com

(2) Instituto Federal da Paraíba (IFPB), Graduada, aamedeiros@live.com

(3) Universidade Federal da Paraíba (UFPB), Professora, angelinadlcosta@yahoo.com.br

\begin{abstract}
RESUMO
As políticas de habitação de interesse social (HIS) têm gerado edificações cuja preocupação com o baixo custo. Torna mais crítica nas unidades destinadas às pessoas com deficiência (PcD). Esse artigo avaliou o desempenho funcional de habitações ditas acessíveis da comunidade Timbó localizada em João Pessoa-PB, levantando parâmetros técnicos e a satisfação do usuário com a residência. A partir da avaliação pós-ocupação (APO). Observou-se que a HIS não é de fato acessível, a localização onde foram implantadas as unidades "acessíveis" tem o acesso dificultado, há baixa qualidade dos materiais empregados na construção; e faltam equipamentos auxiliares básicos, como barras de apoio.
\end{abstract}

Palavras chave: Habitação de interesse social; usuário com deficiência; avaliação pós-ocupação.

\begin{abstract}
Social interest housing policies (HIS) have generated buildings whose concern with the low cost. Increasingly critical in the facilities for people with disabilities ( $P c D$ ). This article evaluated the functional performance of accessible dwellings of the Timbó community located in João Pessoa-PB, raising technical parameters and the satisfaction of the user with the residence. From the postoccupation evaluation (APO). It was observed that HIS is not really accessible, the location where the "accessible" units were installed has difficult access, there is a low quality of the materials used in the construction; and basic auxiliary equipment such as grab bars is lacking.
\end{abstract}

Keywords: Social housing; disabled user; post-occupation evaluation.

\section{INTRODUÇÃO}

Continua sendo um grande desafio a produção de habitação de interesse social dentro de um contexto de déficit habitacional crescente, com experiências que mostram grandes fragilidades especialmente com a inserção urbana destas novas habitações (BRANDÃO, 2016). A prática projetual demonstra diversos problemas que vão além da implantação dos conjuntos habitacionais, como a proposição e replicação em massa do mesmo tipo arquitetônico, independente da diversidade dos perfis familiares da população beneficiada; a baixa qualidade construtiva dessas moradias (tanto em virtude do emprego de materiais de 


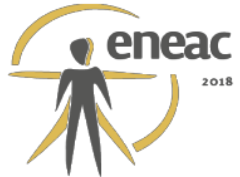

qualidade questionável quanto pela própria execução com falhas); o dimensionamento mínimo de ambientes (em alguns casos abaixo do referencial normativo); e a pouca atenção dada à necessidade de destinar edificações diferenciadas às pessoas com deficiência e/ou mobilidade reduzida; dentre outros pontos de discussão.

Observa-se que muitas vezes não são atendidos os parâmetros mínimos necessários de acessibilidade, conforto ambiental, ergonomia, design universal, entre outros elementos importantes para a melhoria da qualidade de vida dos moradores. E ao se considerar o critério de acessibilidade nas habitações populares, por exemplo, observa-se que embora seja obrigatório, ainda é negligenciado, pois há desde acessos com várias barreiras físicas, utilização de materiais inapropriados, e falta de equipamentos de apoio nos ambientes que apresentam maior dificuldade para o uso (SANTOS et al, 2005).

A acessibilidade começa com um acesso desimpedido, mas perpassa por espaços físicos adequados e inclui educação e conscientização de todos os envolvidos. Em grandes conjuntos habitacionais, percebe-se, contudo, grandes distâncias para deslocamento dos pedestres, escassez de calçadas planejadas para um percurso seguro, pisos malconservados e presença de inúmeros obstáculos móveis ou fixos.

Outro ponto de discussão é o dimensionamento da unidade habitacional. São projetados e construídos ambientes com dimensões abaixo do referencial mínimo, o que prejudica a realização das atividades de vida diária das famílias; o que é agravado quando se trata de usuário com deficiência, pois dificulta sua autonomia restringindo o uso dos espaços.

O fato de considerar essa demanda específica, exige ainda mais dos profissionais e órgãos governamentais envolvidos na etapa projetual; um olhar para as reais necessidades dessa parcela da população e não focar apenas na produção em grande escala, considerando suas especificidades. Por outro lado, Calado e Elali (2016) questionam o ínfimo percentual de casas denominadas acessíveis, e discutem a necessidade de reduzir as desigualdades e incluir as pessoas com deficiência na sociedade, já que o espaço acessível serve não apenas para o deficiente, mas, facilita a vida de todas as pessoas.

O objeto de estudo da pesquisa é a habitação dita "acessível" do Conjunto Habitacional do Timbó (C.H.Timbó) em João Pessoa-PB, construído em uma parceria entre a Secretaria Municipal de Habitação - SEMHAB/JP, e o Programa de Subsídio à Habitação Social PSHS, entregue em 2013. O C.H.Timbó, localiza-se no bairro dos Bancários na região Sul da cidade, e abriga uma parcela da população que já morava na comunidade, e antes habitava em áreas consideradas de risco. A tipologia da unidade residencial segue o esquema de casa geminada sendo térreo +1 pavimento, totalizando 136 unidades, sendo $3 \%$ de unidades acessíveis, o que corresponde a 04 habitações.

O objetivo principal do artigo é avaliar o desempenho funcional das residências adaptadas, identificando suas principais modificações e inadequações, além de conhecer a percepção do usuário com deficiência acerca de sua moradia. Os resultados desse estudo são relevantes no debate sendo uma análise de um fenômeno real, onde o usuário é inserido no processo de avaliação e contribui para compreensão desse cenário de (in)acessibilidade em habitação de interesse social.

\section{METODOLOGIA}

A metodologia dividiu-se nas seguintes etapas: 1- pesquisa referencial e seleção da comunidade: tendo como principal critério de seleção ser um dos poucos exemplos de conjuntos habitacionais em que a Prefeitura Municipal de João Pessoa - PMJP destinou unidades para pessoas com deficiências; 2- Pesquisa documental: levantamento da legislação pertinente, notadamente a NBR 9050 (ABNT, 2015) e Código de obras da cidade 


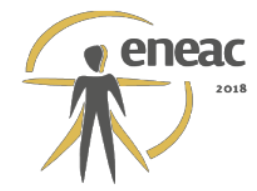

(2001), além de dados oficiais confrontando-os; 3- Pesquisa de campo, que incluiu levantamento físico e fotográfico das unidades ditas acessíveis, e realização de entrevistas semiestruturadas com a pessoa com deficiência $(P c D)$ ou cuidador de cada habitação selecionada, para averiguar as reformas realizadas e os problemas enfrentados na vida diária, respectivamente; 4- Análise e discussão dos resultados: a análise técnica dividida em 04 categorias, sendo seguida pela percepção dos moradores.

\section{3. (IN) ACESSIBILIDADE: SITUAÇÃO TÉCNICA ENCONTRADA X PERCEBIDA PELO USUÁRIO COM DEFICIÊNCIA}

\subsection{Resultados da avaliação técnica}

A avaliação técnica foi dividida em critérios de análises: A) implantação, B) acessos e circulação, C) dimensionamento dos ambientes e $D)$ adequação do mobiliário. Considerando-se a implantação das unidades acessíveis, verificou-se como necessária a inserção de rampas e escadarias para possibilitar o acesso adequado às residências.

Ao se avaliar a implantação dos blocos com as unidades acessíveis, localizadas no terceiro quarteirão, observa-se que estão distantes do acesso principal da comunidade (marcação em vermelho - figura 01); fato agravado por o terreno apresentar grande desnível, dificultando a acessibilidade. Essa implantação deveria ter sido pensada em pontos mais estratégicos, considerando prioritariamente moradores com deficiência, cuja condição de acesso deve ser facilitada.

Figura 1- Esquema gráfico do conjunto habitacional Timbó com característica da topografia, marcação das unidades acessíveis e planta baixa.

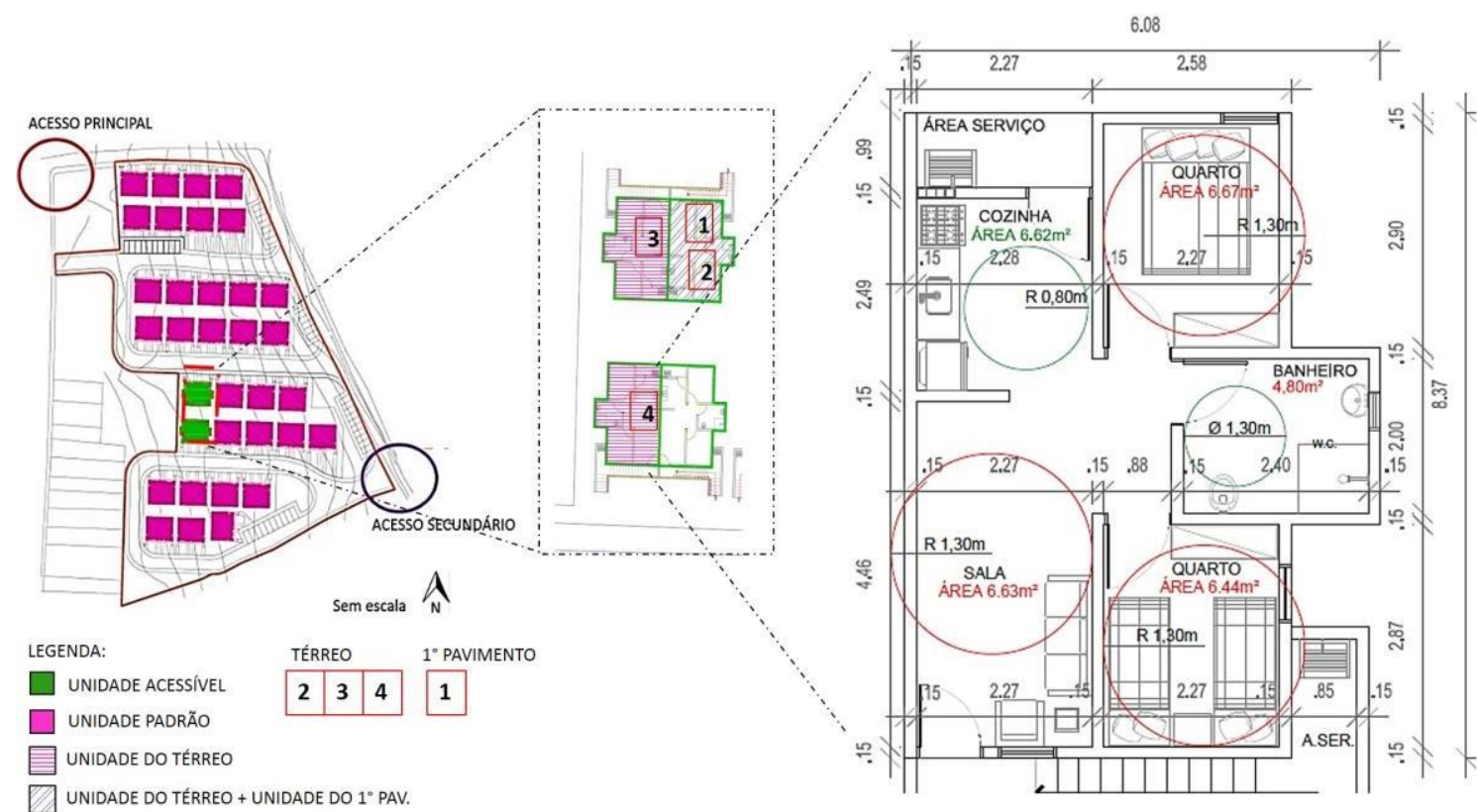

Fonte: Obs.: *Em vermelho: áreas e raio de circunferência abaixo do referencial (Código de Obras, PJMP 2001), adaptado pelos autores. 


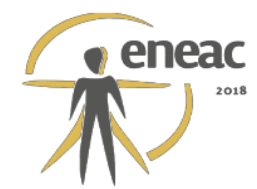

Ao se tratar dos acessos das unidades em estudo (figura 02), as calçadas são obstruídas e apresentam circulação inferior aos $1,20 \mathrm{~m}$ de largura recomendados na norma de acessibilidade para o ambiente construído (ABNT, 2015). Essa obstrução acontece pela presença do mobiliário urbano, como: postes de iluminação pública e lixeiras instaladas em diferentes trechos nas calçadas, além de motos estacionadas nas calçadas. Esse cenário de irregularidades mostra a importância de dividir a calçada em faixas de serviço e livre circulação de pedestres.

Figura 2- Fotografias das fachadas das casas 01, 02 e 03 (à esquerda) e a casa 04 (à direita).
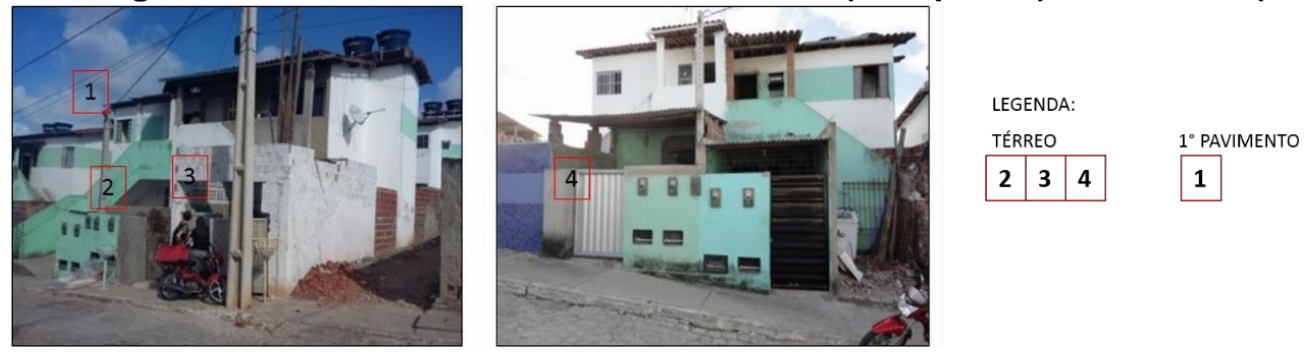

Fonte: FARIAS, MEDEIROS, 2016 - Registro digital do Timbó.

O levantamento da escada de acesso do pavimento superior (casa 01), apontou variações nas dimensões de piso e altura de espelho, o que causa dificuldades para o usuário, que utiliza de arranjos improvisados para facilitar o uso, como a colocação de pedra (marcação em vermelho) para compensar a grande altura do espelho, fora da norma (figura 03). Esse ponto demonstra uma questão básica projetual de inadequação à norma, gerando insegurança e dificuldade de uso, pois cada degrau apresenta uma altura diferenciada. Outro elemento essencial e obrigatório é o corrimão de proteção, que não foi entregue. Sua inexistência faz com que a própria alvenaria seja utilizada como guarda corpo e corrimão.

Figura 3- Fotografias com apontamentos na escada - (à esquerda) com pisos e espelhos irregulares, (à direita) e pedra usada como degrau.
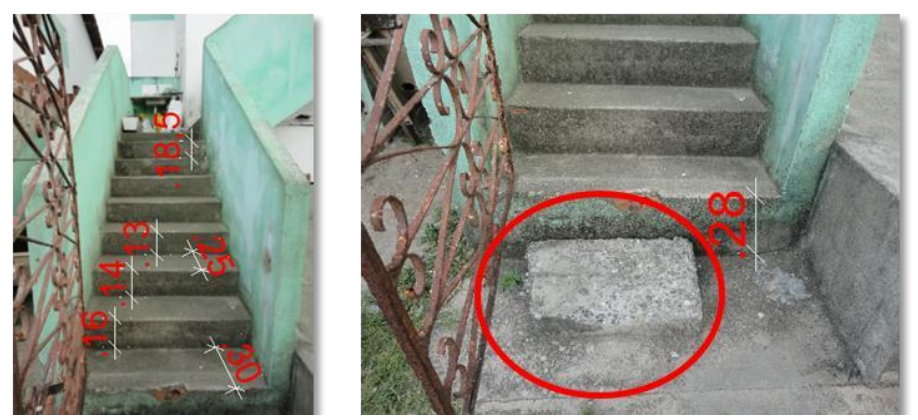

Fonte: FARIAS, MEDEIROS, 2016 - Registro digital do Timbó.

Nas demais casas estudadas (casas 02, 03 e 04), a rampa é o único meio de acesso à edificação, e a rampa da casa 02 foi a única que não foi modificada no período pósocupação (figura 4, à esquerda). As que foram reformadas (casa 03 e 04), não foram alteradas por comodidade, estética, melhor localização ou redução de inclinação, mas sim devido ao projeto original não prever que após a ocupação haveria a divisão dos lotes entre as unidades, com a construção dos muros. Com isso obrigou-se a adaptação da rampa em outro sentido, se adequando à área privativa gerada (figura 04), o que resultou em rampas inadequadas com até 30,08\% de inclinação. 


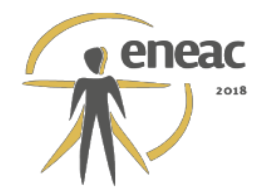

Figura 4- Fotografias com apontamentos nas rampas - (à esquerda) inclinação irregular rampa original - casa 2, (centro) reforma da rampa com desnível entre lances - casa 3, (à direita) rampa reformada com portão de correr cortando o trecho inicial - casa 4.
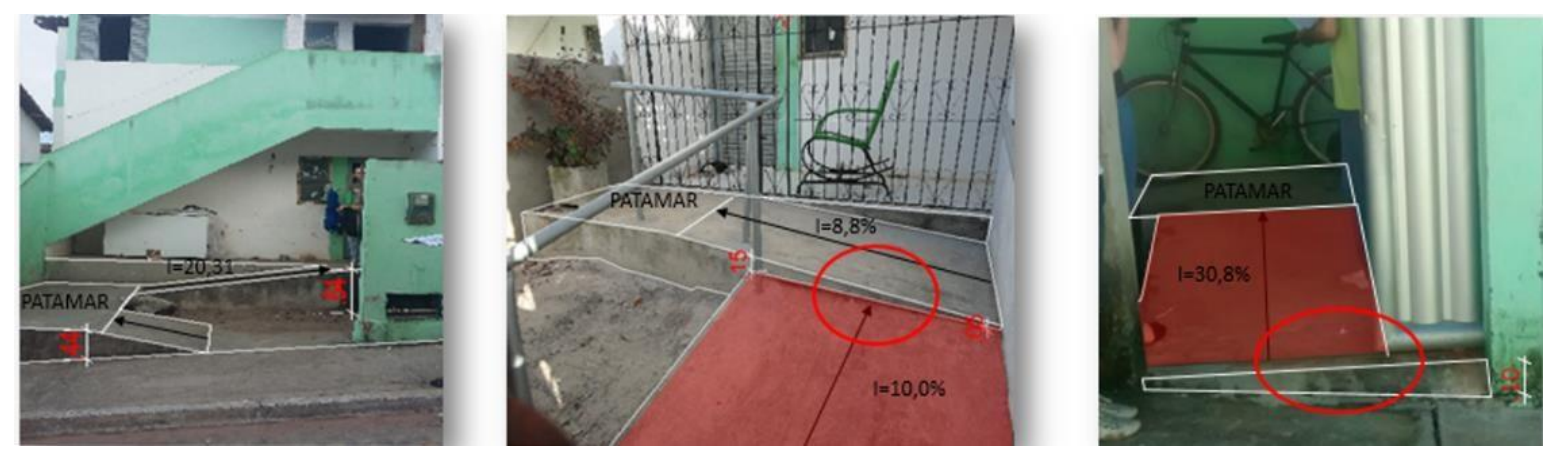

Fonte: FARIAS, MEDEIROS, 2016 - Registro digital do Timbó.

Perdeu-se com isso o papel de facilitar o deslocamento em diferentes níveis, já que a forma como foi executada apresenta-se como um elemento complicador. Observou-se ainda a instalação de corrimão por conta própria. Isso demonstra a importância de os itens básicos serem contemplados no projeto e execução, não se jogando a responsabilidade desse investimento para os moradores, e ainda mais sendo uma população de baixa renda.

As adaptações realizadas pelos moradores ao longo do uso poderiam ser evitadas, caso o projeto original considerasse aspectos como: o uso diário, a cultura e, principalmente a forma de apropriação dos espaços, inclusive por pessoas com deficiência.

Ao se fazer uma comparação entre a unidade padrão e a dita acessível, constata-se uma área de $39,40 \mathrm{~m}^{2}$ e $43,87 \mathrm{~m}^{2}$ respectivamente, distribuídos em dois quartos, sala, cozinha e banheiro, e externamente é localizada a área de serviço, que na unidade térrea apresentase após a cozinha, e no pavimento superior é instalado um tanque de lavar roupa na extensão do patamar da escadaria.

Percebe-se que a estratégia utilizada na unidade "acessível" foi priorizar o aumento da área do banheiro na tentativa de adequação à norma de acessibilidade NBR9050 (ABNT, 2015), por outro lado alguns ambientes são diminuídos, apresentando inclusive o dimensionamento abaixo do mínimo permitido pela legislação, como uma forma de enquadrar área total da unidade nos parâmetros estabelecidos pelos programas habitacionais, o que pode prejudicar o funcionamento das atividades nesses locais (tabela 01).

Tabela 1- Quadro comparativo de áreas entre código de obras e unidades de estudo.

\begin{tabular}{|c|c|c|c|}
\hline Ambiente & Código de Obras & Unidade padrão & Unidade acessível \\
\hline Sala & $8,00 \mathrm{~m}^{2}$ & $9,24 \mathrm{~m}^{2 *}$ & $10,15 \mathrm{~m}^{2 *}$ \\
\hline Quarto & $8,00 \mathrm{~m}^{2}$ & $6,71 \mathrm{~m}^{2}$ & $6,53 \mathrm{~m}^{2}$ \\
\hline Cozinha & $4,00 \mathrm{~m}^{2}$ & $6,71 \mathrm{~m}^{2}$ & $6,59 \mathrm{~m}^{2}$ \\
\hline Banheiro & $3,00 \mathrm{~m}^{2}$ & $5,65 \mathrm{~m}^{2}$ & $5,65 \mathrm{~m}^{2}$ \\
\hline Banheiro & $4,40 \mathrm{~m}^{2}$ & $2,05 \mathrm{~m}^{2}$ & - \\
\hline acessível & (NBR 9050/2015) & - & $4,80 \mathrm{~m}^{2}$ \\
\hline
\end{tabular}

Fonte: Obs.: *Considerada sala (estar + jantar). Em vermelho: áreas abaixo do referencial (Código de Obras, PJMP 2001), adaptado pelos autores. 


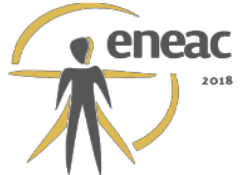

O banheiro acessível possui o dimensionamento um pouco acima do recomendado, mas não foi entregue com as barras de apoio ou qualquer outro elemento de segurança, o que é agravado pela recorrência da instalação da máquina de lavar dentro deste ambiente, já que a área de serviço é desprotegida contra intempéries e não há previsão da sua instalação no âmbito projetual.

Nesta etapa de estudo do mobiliário foi analisada a relação altura x largura $x$ comprimento, principalmente considerando que o usuário é uma PcD ou tem mobilidade reduzida. Nas residências avaliadas é comum a falta de espaço para o mobiliário adequado ergonomicamente já que o existente, geralmente, não atende as condições dos usuários, pois são aproveitados os móveis da residência anterior, o que configura um desafio para adequá-los a estes espaços reduzidos.

A disposição do mobiliário varia de acordo com cada constituição familiar, contudo, o que se pôde notar, é que devido ao pouco espaço livre e dificuldade de acesso e movimentação nos ambientes, de certa forma, os cuidadores "limitam" o local de permanência do PcD ao quarto ou sala, evitando assim maiores esforços de locomoção ao longo do dia. Diante desse cenário de restrição do livre acesso da PcD na sua própria habitação, apresenta-se como uma controvérsia já que esta habitação deveria apresentar as características necessárias voltadas para ela, deixando-a autônoma no seu próprio lar.

A sala que é o ambiente de maior permanência (Farias, 2015), apresenta como ponto comum entre as unidades estudadas uma grande quantidade de mobiliário, o que dificulta também o acesso. Um caso interessante foi na casa 02 (figura 5 -item 02), na qual colchões são colocados no chão, para visitantes e residentes dormirem no ambiente, o que estreita bastante a circulação. Já na sala da casa 04 (figura 5 - item 4), o local que a PcD mais gosta de permanecer e dormir é numa rede armada entre o mobiliário existente, o local é escolhido devido à instalação da tv e por ser um local de maior interação com a família, porém a permanência neste ambiente acaba sendo limitada devido as restrições de espaço o que se reflete no conforto.

Figura 5 - Fotografias mostrando diversas inadequações na sala - (1) altura do mobiliário, casa 1; (2) grande quantidade de móveis estreitando a circulação, casa 2; (3) passagem reduzida devido ao local do mobiliário, casa 3; (4) rede entre mobiliário, casa 4.
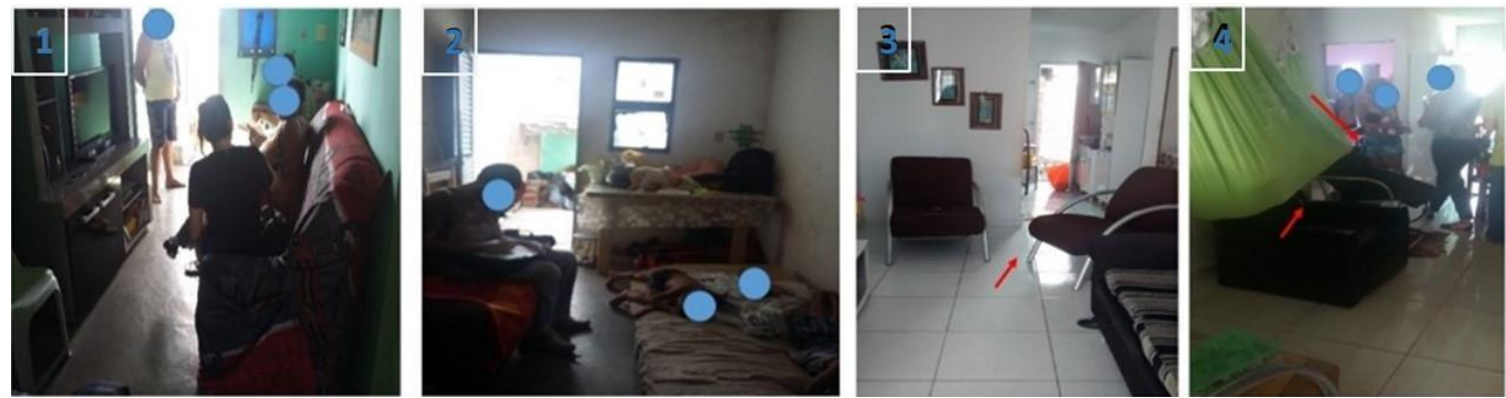

Fonte: FARIAS, MEDEIROS, 2016 - Registro digital do Timbó.

$\mathrm{Na}$ análise dos quartos, segundo a NBR 9050 (ABNT, 2015) para pessoas de uso em pé, a altura de alcance confortável deverá ser de $1,40 \mathrm{~m}$ a $1,55 \mathrm{~m}$. Foi verificado que na casa 01 (figura 6 - item 01) o guarda roupa não traz uma altura confortável ao usuário para utilização de forma independente, podendo ocasionar acidentes como quedas e desgaste funcional. Outras situações também foram observadas como, por exemplo, no quarto de uma idosa cadeirante, na casa 02 (figura 6 - item 02), a abertura da porta possibilita a passagem da cadeira de rodas sem dificuldade, porém o giro é dificultado devido à localização da cama e não foi encontrado no ambiente elemento de apoio, como barras junto à cama, o que 


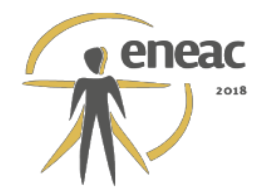

facilitaria a transferência para a cadeira de rodas. Nos quartos da casa 03 (figura 6 - item 03) o mobiliário constitui-se como barreira, dificultando o acesso ao ambiente; já na casa 04 (figura 6 - item 4), com mais pessoas na mesma área reduzida, exige-se maiores desdobramentos, como no uso do guarda roupa, cuja localização dificulta a abertura das portas e a própria utilização.

Figura 6 - Diversas inadequações no quarto - (1) altura do mobiliário inadequada e sem circulação em um dos lados da cama, casa 1; (2) giro da cadeira de rodas dificultado pelo mobiliário, casa 2; (3) presença de mobiliário no acesso, casa 3; (4) dificuldade de abertura e uso do guarda roupa.
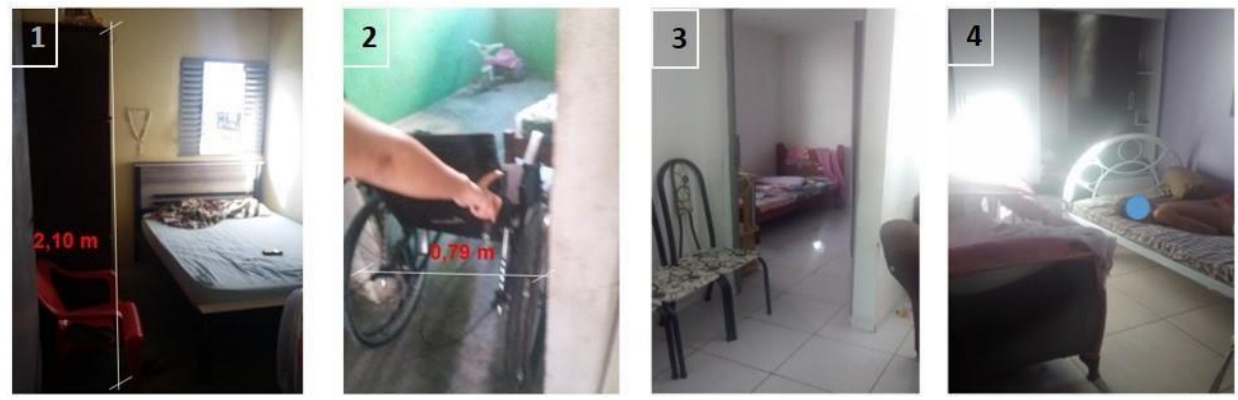

Fonte: FARIAS, MEDEIROS, 2016 - Registro digital do Timbó.

Para a NBR 9050 (ABNT, 2015), na cozinha acessível deve ser garantida a condição de circulação, aproximação e alcance dos utensílios, com altura entre 0,73m e 0,85m; contudo, nas residências estudadas 01 e 02 (figura 7 - item 1 e 2), verifica-se que as bancadas foram instaladas com altura superior $(0,90 \mathrm{~m})$ ao recomendado na norma; além disso, o ambiente apresenta grande quantidade de mobiliário no pequeno espaço, o que dificulta não só o acesso, mas potencializa o risco de queimaduras e cortes devido ao local agregar diversas funções: preparo, manutenção, cozimento, armazenamento, limpeza, fazer as refeições e convívio social.

$\mathrm{Na}$ casa 03 (figura 7 - item 03), a cozinha apresenta perdas em suas funções devido ao espaço e a forma de distribuição do layout, onde a mesa junto ao fogão impossibilita a abertura do forno devido a essa disposição inapropriada. Já na casa 04 (figura 7, item 04), o micro-ondas está numa altura que pode trazer risco de acidentes $(1,65 \mathrm{~m})$, já que o recomendado é $1,10 \mathrm{~m}$ a $1,25 \mathrm{~m}$ (IIDA, 2005). Ao se analisar o layout desse espaço, o usuário adapta e faz diferentes arranjos, mesmo não sendo adequados como ilustram as imagens.

Figura 7 - Fotografias mostrando diversas inadequações na cozinha - (1) layout comprometido e altura inadequada da bancada, (2) altura da bancada, (3) restrição do uso do fogão, (4) altura do micro-ondas acima do recomendado.
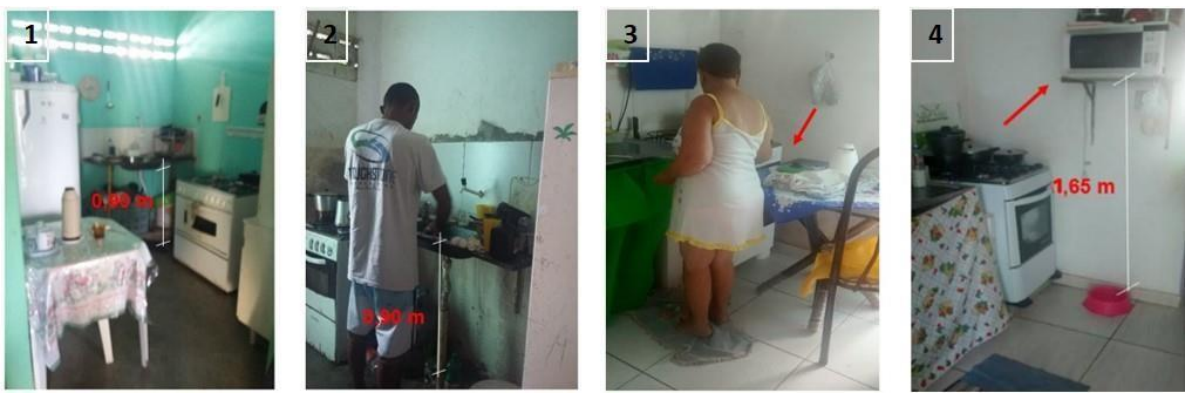


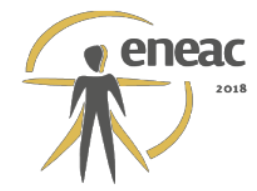

Fonte: FARIAS, MEDEIROS, 2016 - Registro digital do Timbó.

O banheiro é um dos locais onde ocorrem mais acidentes por ter área molhada, situação agravada pelo emprego de piso derrapante (Figura 8). O uso da máquina de lavar no interior do banheiro mostra um uso não pensado, mas necessário por não haver espaço para esse equipamento na área de serviço. Na opinião dos usuários, o banheiro é superdimensionado, por isso é aproveitado também para instalação de uma bancada maior para utilizar como área de serviço (figura 8 , item 03). Essa realidade comum mostra a necessidade de se prever esse equipamento já no projeto.

Figura 8 - Inadequações no banheiro, (1) máquina de lavar, casa 1; (2) altura da bancada e inexistência de barras de apoio, casa 2;(3) instalação de bancada para lavagem de roupa, casa 3; e (4) impermeabilização de parede insuficiente, casa 4.
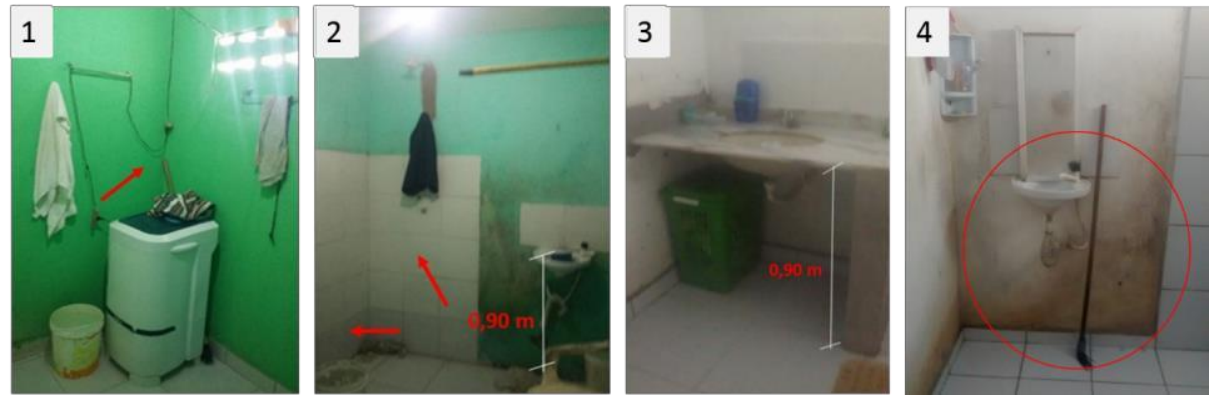

Fonte: FARIAS, MEDEIROS, 2016 - Registro digital do Timbó.

\subsection{Resultados da percepção dos usuários com deficiência}

Foram realizadas entrevistas semiestruturadas com um representante de cada unidade acessível: a própria pessoa com deficiência ou o seu cuidador, o que mostra os diferentes perfis familiares (tabela 02) vivendo na mesma tipologia arquitetônica. Ressalta-se que todos os usuários moram há 04 anos nas residências, desde a entrega do conjunto habitacional, o que já possibilitou encontrar as modificações no ambiente construído ao longo do tempo.

Tabela 2- Perfil dos usuários das unidades acessíveis.

\begin{tabular}{|c|c|c|c|c|c|c|}
\hline Casa & Pavimento & Sexo & Idade & Deficiência & $\begin{array}{c}\text { Benefício } \\
\text { governo }\end{array}$ & $\begin{array}{c}\text { No de } \\
\text { moradores }\end{array}$ \\
\hline 1 & Superior & Fem. & $\begin{array}{c}61 \\
\text { anos }\end{array}$ & $\begin{array}{c}\text { Mobilidade reduzida por } \\
\text { possui hérnias de disco. } \\
\text { Filho com retardo mental }\end{array}$ & Aposentadoria & 2 \\
\hline 2 & Térreo & Fem. & $\begin{array}{c}\text { Anos } \\
\text { anos }\end{array}$ & $\begin{array}{c}\text { Tornou-se cadeirante } \\
\text { após A.V.E. }\end{array}$ & Aposentadoria & 5 \\
\hline 3 & Térreo & Fem. & $\begin{array}{c}60 \\
\text { anos }\end{array}$ & $\begin{array}{c}\text { Mobilidade reduzida } \\
\text { após trombose }\end{array}$ & Auxílio-doença & 1 \\
\hline
\end{tabular}




\begin{tabular}{|c|c|c|c|c|c|c|}
\hline 4 & Térreo & Masc. & $\begin{array}{c}21 \\
\text { anos }\end{array}$ & $\begin{array}{l}\text { É cadeirante com } \\
\text { paralisia cerebral }\end{array}$ & Auxílio-doença & 7 \\
\hline
\end{tabular}

Fonte: Elaborado pelos autores.

Para entender a satisfação da atual moradia é necessário conhecer as condições da residência anterior, sendo questionados sobre quais eram os maiores problemas enfrentados, foram relatados: a localização ao lado da barreira, a preocupação com chuva e desabamento, a dificuldade de subir a ladeira íngreme de acesso, a estrutura precária, o tamanho reduzido da unidade e ausência de laje estrutural - o que denota problemas graves. Em contrapartida, foi elencado como aspecto positivo sobre a casa anterior o terreno ser maior do que o atual da unidade entregue. Fato compreensível e diretamente associado ao número de pessoas que habita a unidade (tabela 2).

Questionados sobre como classificam a residência os usuários identificaram como o ponto melhor avaliado o banheiro: o tamanho, a localização e a facilidade de realizar as atividades no ambiente. De fato, a boa aceitação se deve a dimensão do ambiente estar próxima ao recomendado pela Norma NBR 9050 (ABNT, 2015) e por isso foram associadas outras funções neste ambiente, como área de serviço. $O$ critério que mais dividiu opinião foi 0 acesso à unidade residencial, 02 usuários sinalizaram como sendo "bom", 01 avaliou "ruim", e 01 como "péssimo", esse último é residente do pavimento superior o que exige o uso da escadaria (casa 1). Essa variação pode ser associada à inclinação inapropriada das rampas, e dificuldade em não ter os apoios (guarda-corpo ou corrimão), já no caso da escadaria, a mobilidade reduzida da usuária dificulta ainda mais o uso.

Outro critério importante é o tamanho dos ambientes, como o quarto e a cozinha, que tiveram avaliações divididas entre "bom" e "ruim". As PcDs inclusive não utilizam a cozinha devido à dificuldade de deslocamento no ambiente e dimensões reduzidas, agravadas pela quantidade de mobiliário no local, com isso sua permanência torna-se restrita à sala e ao quarto. Em relação ao dormitório, quanto maior o número de moradores, mais complicada é a utilização da cadeira de rodas no ambiente, pois há um conflito entre mobiliário existente e até mesmo a perda do espaço para o giro da porta.

Em relação ao banheiro, o ponto mais criticado foi a falta das barras de apoio para transferência, o que dificulta a utilização das pessoas com deficiência e exige muito mais esforço no auxílio dos cuidadores. Esse ponto entre outros converge para os resultados na análise técnica o que mostra que os usuários perceberam essas necessidades, dando uma maior importância ao que é vivenciado por eles. Outra discussão foi o retorno da água do banheiro para o interior da sala, por não haver desnível entre esses ambientes e o caimento do piso em direção ao ralo ser insuficiente. Devido a isso, na casa 1 construiu-se uma pequena barreira de cimento para conter o retorno da água, com isso, gerou uma barreira física entre os espaços.

Perguntados sobre qual é o ambiente de maior permanência, as repostas foram: quarto (1) e sala (3), devido à sua localização central e de fácil acesso aos demais ambientes, sendo a área de maior interação com os outros membros da residência, e pela instalação da televisão. Quanto ao atendimento das necessidades nesse ambiente de maior permanência sem ter sido feitas modificações, metade dos entrevistados analisaram que "sim" já a outra metade informa que "não", devido à dificuldade de deslocamento no ambiente. Outra questão procurou compreender se os ambientes ajudam na realização das atividades, sendo 01 usuários afirmou que "sim", já os outros 03 apontaram que "não", devido a alguns fatores como, dificuldade de movimentação nos ambientes, o calor e a insolação direta exigirem meios de ventilação mecânica (ventilador) durante boa parte do dia.

Quando questionados se há necessidade de fazer alguma outra reforma na residência para melhor o uso dos ambientes 03 usuários informaram que "sim", e apenas 01 disse que 


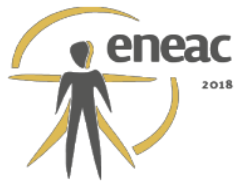

"não", pois já foi realizada (casa 3). Sobre as necessidades de modificação da unidade residencial, um ponto citado por todos foi melhorar a acústica entre as unidades, pois qualquer barulho do pavimento superior é escutado no térreo devido à baixa espessura da laje e falta de tratamento acústico adequado. Já as demais necessidades de alterações são: trocar para unidade térrea (casa 1); aumento da área dos cômodos, quarto e cozinha (1); inserção de proteção nas esquadrias externas para diminuir a insolação dentro dos ambientes (1); e reduzir o calor interno da edificação (1). É importante perceber como os usuários relatam necessidades diversas que englobam desde aspectos relativos à privacidade, como questões de conforto ambiental e algumas que estão associadas diretamente com uma maior acessibilidade, como o piso da unidade e dimensões dos ambientes.

E por fim, avaliou-se o nível de satisfação dos moradores quanto à moradia, tendo respostas variadas: metade mostrou-se extremamente "insatisfeito", e a outra metade divide-se em "satisfeito" e "muito satisfeito". Para entender essa variação é preciso considerar alguns pontos, por exemplo, como no caso da maior insatisfação, ser um usuário que não conseguiu uma casa no térreo (casa 1) e também o fator do tamanho reduzido da unidade residencial. Já a parcela que se mostra satisfeita, apesar de considerar um problema essa redução de área, tinha casas anteriores com muitas fragilidades.

\section{EM BUSCA DE UMA ACESSIBILIDADE EFETIVA}

O intuito do trabalho foi conhecer dois olhares: o técnico e do usuário com deficiência, morador da unidade habitacional. Foi exposto um diagnóstico criterioso da realidade encontrada e vivenciada no estudo de caso, e fica evidente a necessidade de adequação inclusive do conceito de "unidade acessível" entregue para aquela população.

A satisfação verificada dos moradores com sua moradia apresenta-se como um peculiar achado de pesquisa, influenciado fortemente tanto pela precariedade da moradia anterior (que apresentava em condições insalubres), bem como no desconhecimento (falta de vivência) de espaços com maior qualidade ambiental.

Observou-se ainda uma convergência das maiores necessidades externadas pelos moradores do C. H. Timbó, refletidas nas reformas realizadas mesmo em pouco tempo de uso. Destacam-se:

- A unidade considerada pela gestão municipal como "acessível" na verdade não é acessível em sua totalidade, já que comporta apenas um dimensionamento maior do banheiro e a construção da rampa de acesso no pavimento térreo;

- O projeto de acessibilidade para a unidade habitacional foi pensado considerando, unicamente o uso da cadeira de rodas (e no acesso ao banheiro), o que é uma visão muito limitada, uma vez que desconsidera outras deficiências, que por sua vez têm outras necessidades;

- A própria implantação dos blocos das unidades "acessíveis" já se configura como uma primeira barreira física, pois a localização é distante do acesso principal da comunidade e impõe um maior deslocamento, dificultado pela topografia íngreme do lugar;

- O fator financeiro foi um importante limitador das reformas realizadas ao longo do uso;

- As calçadas dos blocos deveriam possibilitar o deslocamento das PcDs para as áreas do conjunto, no entanto devido ao dimensionamento reduzido das mesmas além de barreiras físicas instaladas, as pessoas com deficiências ficam restritas ao interior 


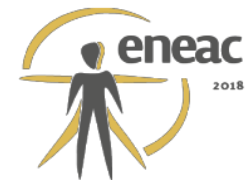

das moradias;

- A existência de rampa construída com inclinação superior à recomendada e entregue sem corrimão impõe o ônus da adaptação para o usuário. Além disso, a construção dos muros que separam as unidades térreas no pós-uso é realizada ocupando a área da rampa original, cria a necessidade da modificação da mesma, realizada pelo usuário sem qualquer orientação técnica, gerando rampas inadequadas;

- A qualidade dos materiais empregados foi outro problema encontrado, apenas o banheiro foi entregue com piso cerâmico, porém inadequado ao uso (derrapante), e sem impermeabilização nas paredes na cozinha e banheiro. Verificou-se ainda baixa qualidade das pias, tanques e esquadrias;

- No lugar do uso de esquadrias no banheiro e cozinha, foram especificados cobogós (poucas unidades), que são insuficientes para proporcionar a renovação do ar e iluminação natural nos ambientes, além de dificultar a ventilação no interior da casa, prejudicando o conforto térmico;

- A estratégia de projeto para o dimensionamento do banheiro de acordo com a norma NBR 9050 (ABNT, 2015) foi a diminuição das áreas de outros ambientes, o que na unidade padrão já apresentava dimensionamento abaixo do mínimo recomendado, e na unidade "acessível" fica ainda mais reduzido, prejudicando em demasia o uso e a realização das atividades nos ambientes, principalmente por PcD e/ou mobilidade reduzida;

- Áreas de serviço instaladas em local com dimensionamento reduzido, sem proteção contra intempéries, e sem previsão de instalação da máquina de lavar no projeto original, contribuem para o compartilhamento do uso no interior do banheiro, cozinha ou circulação.

Enfim, é necessário repensar a forma de projetar a habitação mínima acessível, pois acessibilidade vai muito além de um banheiro dimensionalmente adequado (e dentro da norma) ou com barras de apoio. É imprescindível adotar uma visão mais abrangente desde o início do processo e que inclua e garanta o acesso desde a implantação no lote, chegando no nível do detalhe de alcance adequado para pontos elétricos, por exemplo.

O uso indiscriminado e inadequado da terminologia "acessível" também deve ser reconsiderado. É necessário projetar de forma universal e não pensar apenas em pessoas com deficiência física (especialmente cadeirante) uma vez que a população tem deficiências

diversas. Por fim, faz-se necessário ainda maior rigor no emprego dos materiais construtivos, e uma fiscalização criteriosa e comprometida que exija no mínimo, que se cumpram os parâmetros estabelecidos pelas normas.

\section{REFERÊNCIAS BIBLIOGRÁFICAS}

ABIKO, Alex Kenia. Introdução à gestão habitacional. Texto técnico / Escola Politécnica da USP. Departamento de Engenharia de Construção Civil. São Paulo, 1995. 31p.

ASSOCIAÇÃO BRASILEIRA DE NORMAS TÉCNICAS. NBR 9050: Acessibilidade a edificações, espaço, mobiliário e equipamento urbano. Rio de Janeiro: ABNT, 2015.

ASSOCIAÇÃO BRASILEIRA DE NORMAS TÉCNICAS. NBR 15.575: Desempenho de edificações habitacionais. Rio de Janeiro: ABNT, 2013.

BITENCOURT, F. Ergonomia e Conforto humano. Rio de janeiro Book's, $1^{\circ}$ edição 2011.

BRANDÃO, Z. Habitação + cidade: diretrizes pedagógicas para um mestrado profissional em 


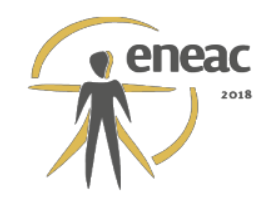

desenho urbano com foco em habitação social. In: Revista Projetar - Projeto e percepção do ambiente, v.1, n.2, agosto 2016.

CALADO, G. C.; ELALI, G. A. Acessibilidade em habitação de interesse social: estudo de caso no Residencial Waldemar Rolim. VI Encontro Nacional de Ergonomia do Ambiente Construído ENAC. Recife, 2016.

CAMBIAGHI, S. Desenho universal: métodos e técnicas para arquitetos e urbanistas. SENAC São Paulo, 2007.

CARVALHO, L. R. Ergonomia e o trabalho do portador de necessidade motora específica: o caso do cadeirante. 2001. 109 f. Dissertação (Mestrado em Engenharia de Produção) - Programa de Pós-Graduação em Engenharia de Produção, Universidade Federal de Santa Catarina, Florianópolis, 2001.

CíRICO, L. A. Por dentro do espaço habitável: uma avaliação ergonômica de apartamentos e seus reflexos nos usuários. 2001. 140 f. Dissertação (Mestrado em Engenharia de Produção) Programa de Pós-Graduação em Engenharia de Produção, Universidade Federal de Santa Catarina, Florianópolis, 2001.

DILIGENTI, M. P. Sustentabilidade e Habitação de Interesse Social: movimentos sociais e a (re) significação do lugar. In: Simpósio Temático: Sustentabilidade na Habitação de Interesse Social: cultural, social, ambiental e econômica, Rio de Janeiro, 2010.

FARIAS, G, G, P, M. Avaliação pós-ocupação de conjuntos habitacionais de interesse social: Um estudo de caso nos conjuntos Timbó e Gadanho em João Pessoa-PB. Trabalho Final de Graduação, Arquitetura e Urbanismo, Universidade Federal da Paraíba, João Pessoa, 2015.

IIDA, I. Ergonomia: Projeto e Produção. 2. ed. São Paulo: Editora Edgard Blücher LTDA, 2005.

SANTOS, A. dos; SANTOS, L. K. S.; RIBAS, V. G. Acessibilidade de habitações de interesse social ao cadeirante: um estudo de caso. Ambiente Construído, v.5, n.1, p.55-75. Porto Alegre, 2005.

SECRETARIA DE PLANEJAMENTO. Código de obras do município de João Pessoa. João Pessoa, agosto de 2001.

SECRETARIA MUNICIPAL DE HABITAÇÃO SOCIAL / PMJP. Habitação de Interesse Social em João Pessoa de 2006 a 2012. João Pessoa, dezembro 2012.

VILLAROUCO, V. Tratando de ambientes ergonomicamente adequados: seriam ergoambientes? In: MONT'ALVÃO, C; VILLAROUCO, V. (Orgs.). Um novo olhar para o projeto: a ergonomia no ambiente construído. Rio de Janeiro: Ed. 2AB, 2011. 